cavities. The margins of these openings were united in two cases with a continuous catgut suture ( $F$ ig. 9), and in one with interrupted

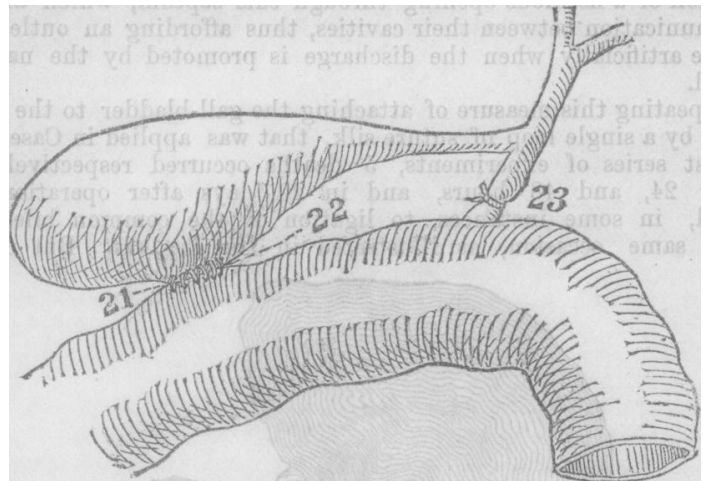

Fig. 9.-Exterior view of operation by punch. 21-22. Stitches in margin of aperture through walls of gall-bladder and duodenum. 23. Ligation of common duct.

suture of Snowdon's iron-dyed silk, as exhibited in Fig. 10. In the two

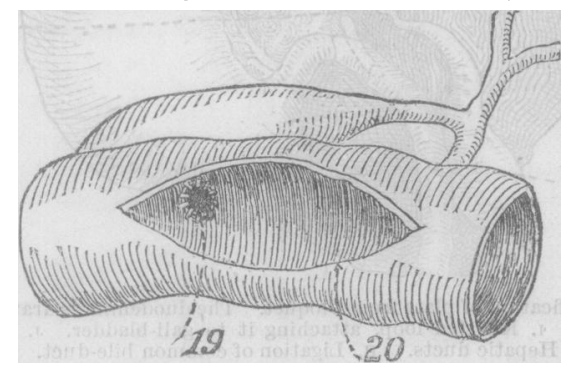

Fig. 10.-Result of direct opening in walls. 19. Orifice with sutured margin. 20. Incision into dundenum.

cases in which the common duct was ligatured, the necropsies showed some yielding of the suture around the circular openings in the walls, and hence escape of bile into the peritoneal cavity. It was inferred. that the contractile tissue of the duodenal canal led to the closure of the orifice made by the punch, as is sometimes observed in the perforations of small balls in gunshot wounds of the intestines, which prevented the passage of the bile directly from the gall-bladder into the duodenum, so that it was forced out between the stitches. With proper precautions, in the removal of a larger portion of tissue from the duodenal wall, so as to make allowance for its contractility, and the union of the margins by Galy's suture, instead of the ordinary continued or interrupted suture, success is likely to follow this operation, and it may be used to separate a circular disc of their walls in cases not demanding immediate communication.

Only three dogs of the fifteen in this series of experiments survived the primary operations, and I sought, by secondary experimentation on these, to test the practicability of turning the bile entirely into the artificial channel, which there was sufficient grounds to conclude had been made by the silk loop cutting an opening through the attached walls. The object of re-opening the abdominal cavity was to ligature the common duct, which remained open in each of these cases; but the adhesions of the duodenum with the lower surface of the liver completely shut out any view of the ducts, so that only the touch could be used in attempting to pass the ligature. As a consequence of this uncertain guide in the proceeding, failure resulted in my own efforts, and in those undertaken, at my request, by a colleague, to secure the common duct.

In a second laparotomy, one month and three days after the primary operation upon one of these subjects, death took place within forty-eight hours.

Another animal, that underwent a second laparotomy one month after the attachment of the gall-bladder and duodenum, survived this, and at the expiration of a like period, was subjected to a third opening of the abdomen. The wall of the duodenum was incised, and there was a cicatricial depression in the septum, indicating that an opening had recently existed, into which a trocar passed with slight resistance, re-establishing the communication with the cavity of the gall-bladder. This dog died four days subsequently, two months and iour davs having elansed from the primary operation.
The third, that resisted the attachment of the gall-bladder and duodenum, was, at the expiration of twenty-five days, submitted by my colleague, Dr. W. D. Bizzell, to a second operation, and he verified the firm union of the walls of the gall-bladder and duodenum around the point of suture. He felt assured that an opening existed through this septum for the flow of bile, and attempted, without effect, to ligature the common duct.

The abdominal cavity of this animal was opened for the third time two months subsequently, when it was corroborated by a number of medical men present, that a strong attachment existed between the gall-bladder and duodenum, while it was inferred that the sac was drained by an artificial outlet into the duodenal canal. After tearing loose some of the adhesions, with a view to expose the common duct, another fruitless attempt was made to pass a ligature around it. This dog died ten days after the third laparotomy, and the necropsy showed a free communication between the gall-bladder and duodenum, from the action of the single loop of silk thread passed through their walls more than three months previonsly. There was also found to exist a solid compact union of their walls around this aperture, resulting from the adhesive inflammation set un between their serous surfaces, which had been brought in contact by the loon of suture. It was ascertained, by exploration, that the luctus choledochus communis was pervious, but that one of the branches of the hepatic duct had been ligatured by mistake, and that there was partial disintegra. tion of the parenchymatous structure of the corresponding lobe of the liver, which most probably led to the fatal result.

It is evident that the preservation of this artificial communication between the gall-bladder and duodenum for three months and five days, while the natural outlet was open, affords strong ground for belief in the maintenance of such an outlet for the bile, when obstruction of the common bile duct exists, as in cases requiring surgical interference in the human subject.

\section{FIFTY CASES OF OVARIOTOMY.}

\section{By SKENE KEITH, M.B., C.M.EdIN., F.R.C.S. ED.}

THE point of greatest interest in $\mathrm{my}$ second series of fifty cases of ovariotomy, is to be seen in the diminished number of tumours which had been tapped before operation. Only eleven of the number, or 22 per cent., had been treated in this way, as against 32 per cent. in the first fifty. This is most satisfactory, and I hope to be able to show, ere long, that the tapping of an ovarian tumour by anyone other than the surgeon who is to have charge of the case, is as rare in Scotland as it has been for some years in England.

The advance which has been made in abdominal surgery, since the operation of ovariotomy was established by Sir Spencer Wells in the south, and by Dr. Keith in the north, is shown very distinctly by comparing the death-rate of those who have begun their abdominal surgery in the last few years, with the mortality in the first fifty cases of ovariotomy, of several of the older operators. In Dr. Keith's first fifty completed operations there were ten deaths; advancing a stage of rather more than ten years, we find that beginners still had a heavy death-list. Thornton, Bantock and Tait having nine, fourteen and nineteen deaths respectively in their first fifties. A second stage onwards of about seven years, and Mr. Meredith and myself are able to show less than one-third the number of the deaths of the surgeons already mentioned. What is the reason of the greatly diminished number of deaths? One of the most important, and ore of which little notice has been taken, is that the operations ars less severe than they used to be. Twenty-five years ago, when it was almost a crime to remove an ovarian tumour, the unfortunates who had them, were allowed to live as long as possible : and, when it was certain that their lives were worth little, they were then, and not till then, handed over to the surgeon, almost as to the executioner. In the Edinburgh Medical Journal of August 1864, Dr. Keith mentions that he had refused to operate on three cases only up to that time, and that one of these died in forty-eight hours, another in a week, and the third three weeks after being first seen by him. A second and most important factor in the production of the diminished death-rate is the principle of perfect cleanliness of Lister. Even those who scoff most, would never think of putting a dirty finger, or sponge, or instrument into the abdomen, yet this regular and systematic use of the nailbrush is the direct outcome of Lister's antiseptics.

Increased experience is not to be lost sight of. Now, no one ought to do abdominal surgery unless he has watched others at work, and one onght not to hear it gravely suggested, as I have, when there 
was some doubt as to whether the peritoneum had been opened or not, that the layers of the abdominal wall ought to be counted. This is hard to believe, but it is a fact. The intra-peritoneal treatment of the pedicle has probably something to do with our present success; though I have little doubt that almost, if not quite as good results could be got with the clamp, if proper care were taken to dry the stump, and to prevent septic matter reaching the wound or the peritoneal cavity. The real objection to this instrument is, that the wound cannot heal in its whole extent by first intention. Drainage saves the lives of some. It is strange how the use of the tube was struggled against, long after it had been adopted in general surgery. All manner of objections were made. It was said to be the cause of hernia, and that there was danger of omentum entering the holes and becoming strangulated. Both these objections were directed not to the proper but to the improper use of the instrument. It is quite conceivable that a tube as thick as one's thumb may weaken the abdominal wall, or that holes made to suit such a tube might allow omentum to enter; but such a one is far too large, and I was much surprised when first shown a Keith's tube of this size. We have also better instruments, and we know better how to take care of our patients after operation. The routine practice of giving so much opium so many times a day is gradually giving place to the more enlightened plan of using the drug in suitable cases, and with some definite object, though some have gone to the opposite extreme, and say that they never order it under any circumstances. These are the chief reasons why fewer women die after ovariotomy than used to die; yet, although the mortality of specialists is reduced to a small percentage, the general mortality after ovariotomy in this country is prob. ably nearer 30 than 20 per cent. Some time ago I heard of an obstetrician having five deaths in succession after this operation.

It is interesting to watch how even in the comparatively short history of ovariotomy, methods of treatment have been tried, found wanting, discarded, and then, after a few years, again brought forward ; or how great stress has been laid on one particular part of the operation, how it is next thought to be of little importance, and how, again, it is written about and made much of. For example, about twenty years ago Dr. Keith used often to wash out the peritoneal cavity with warm water; five years ago I saw this practice carried out in America, and now it has been taken up by English abdominal surgeons as one of the most recent advances. The length of the incision has been again pushed into prominence. Many years ago Sir Spencer Wells showed that the mortality was greater when a long, rather than a short, incision had been used. The natural explanation of this is that a longer incision is required when the tumour is badly adherent, and, when it cannot be much diminished in size either by the trocar or by breaking down with the hand. The following sentence from the Lancet, nineteen years ago, shows this pretty conclusively. "In the case of single, or nearly single, unattached cysts nothing could be simpler than the operation, and in several the cicatrix is not more noticeable than the umbilicus."

The number of broad ligament or parovarian cysts is much under Mr. Tait's average of 10 per cent., though in his last list of cases the number had gone up to eighteen in the hundred. Here the proportion of these cysts is decidedly under 10 per cent., and the majority of these are cured by tapping, abdominal section being required only in exceptional cases. Malignant cysts of the parovarium do not seem to flourish in this part of the world. It remains a mystery why surgeons will not even try to cure these cysts by simple means-a trocar and cannula not larger than a No. 4 or 5 catheter is all that is required.

To make my list of abdominal sections complete, as I believe that this the only way of giving a correct idea of the work which is being done, eighteen cases of the removal of the uterine appendages, one case of hysterectomy, four exploratory, or incomplete, operations, with

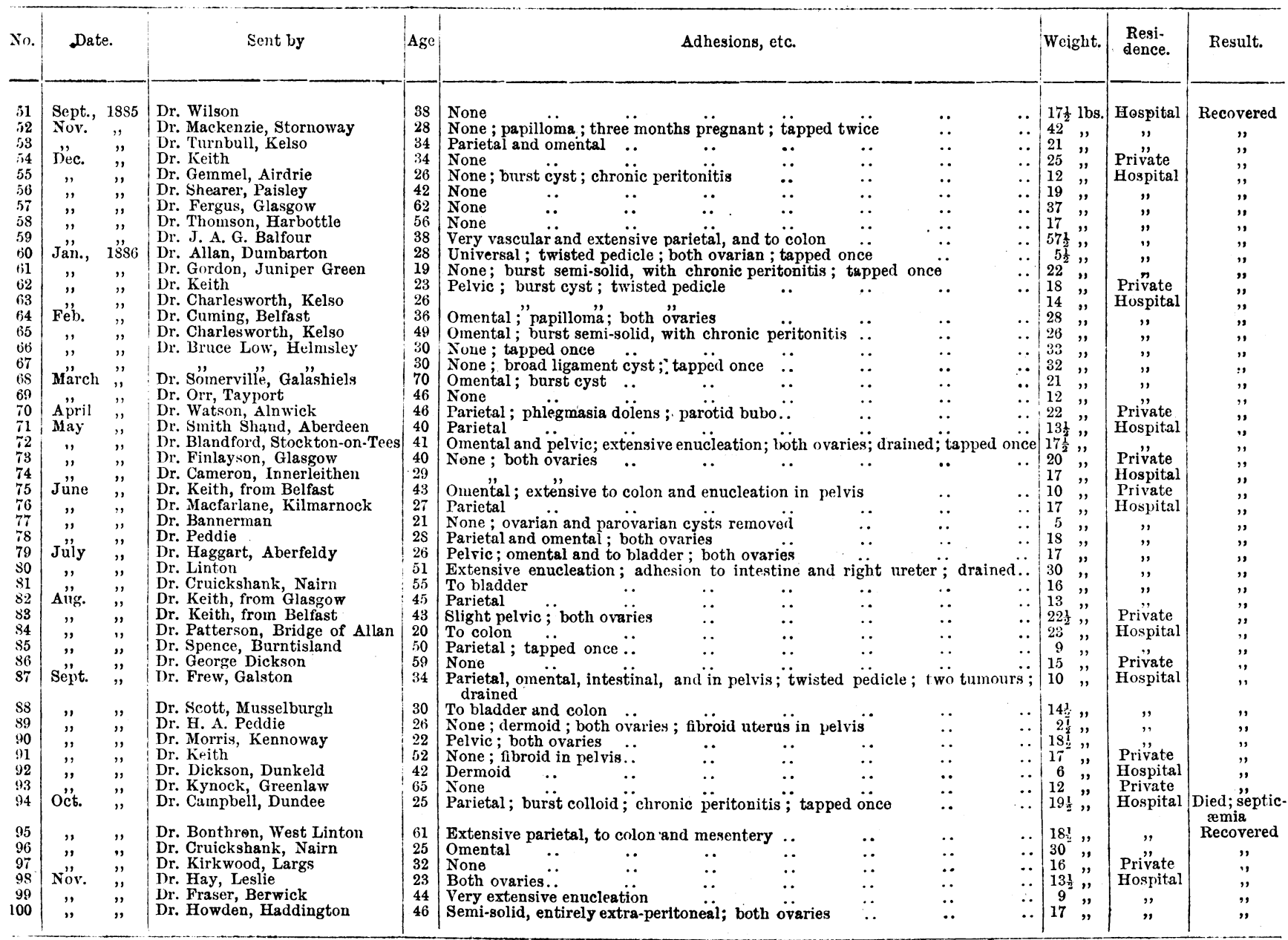


one death and one fatal case of the removal of a uterine fibroid must be added, bring up the total of cases where I have opened the abdomen to 131 , with six deaths. At present, a smaller death.rate accompanies the operation of ovariotomy than that of the other abdominal sections, This is seen at once from the figures already given-3 per cent. for o variotomy, 10 per cent. for all other cases-or even more markedly when we compare Mr. Tait's last list of removal of ovarian and parovarian tumours with what one knows of his results in other abdominal operations. During one of the two years when this long list was being made-the only one for which I have seen the report of the Birmingham Women's Hospital-the abdomen was opened fifty-six times by this operator in that hospital. Out of these fifty-six operations, eight were fatal, or, in other words, one woman out of every seven died, on whom Mr. Tait that year performed abdominal section in the hospital. These results have certainly not helped to destroy my fear of the peritoneum, nor, to use Mr. Tait's own words, do they justify me in opening that sacred sac very much as one opens one's pocket.

The incomplete or exploratory operations consisted of two cases of ovarian tumours, where I expressed the opinion that it would probably be impossible to remove the growths; but, as on each occasion I had travelled a long distance to see the patients, and as both were very anxious to have something tried, exploratory incision was advised. In the fatal case, the growth was found to be a multilocular tumour, so adherent as to defy removal, and in addition there were cancerous masses in the omentum and mesentery. The second case occurred in an old lady, aged 75. The tumour weighed fully thirty pounds, and at least one-half of its anterior surface was covered by adherent intestine. An incision was made to see if the adherent bowel could be separated easily or not. Unfortunately-or perhaps fortunately - the intestinal adhesion was very vascular; and, taking into consideration the age of the patient, who had attained to five years beyond the time allotted to man, I determined to empty the sac and close the wound. The contents of the sac were too viscid to flow through the trocar; the opening was therefore enlarged, the contents emptied, the interior of the cyst washed out with warm water, and the opening closed round a large rubber drainage-tube. The sac suppurated, giving rise to almost no disturbance, rapidly closed, and in a few weeks the old lady was able to be downstairs, and is now quite well. The two other cases were not begun as exploratory operatious. In one, I eutirely failed to remove the uterine appendages, and all that was done was to separate the uterus from its close connection to the tissues over the sacrum. Strangely enough, this has relieved the woman of her backache, though in other respects she has not improved. The last case was one of a large semi-solid ovarian tumour, surrounded by ascitic fluid. Following our usnal custom, the ascitic fluid was drawn off, and examined microscopically. No evidence of malignant disease was found in it, although when the abdomen was opened, cancerous masses were seen, not only on the surface of the tumour, but also on the peritoneum and on the liver. In such a case, no good could have resulted from the removal of the tumour, so the wound was closed. The poor woman lived for eight or nine months. I think it right to make a distinction between cases which are begun as exploratory and those which, from error in diagnosis or other cause, have to end as such. For diagnostic purposes no opera tion has been required, and there has been no mistake in diagnosis.

\section{A SUCCESSFUL CASE OF PARTIAL EXCISION OF THE LARYNX, ON ACCOUNT OF INTRA- LARYNGEAL EPITHELIOMA. \\ WITH REMARKS,}

Bx LENNOX BROWNE, F.R.C.S.ED.,

Senior Surgeon to the Central London Throat and Ear Hospital.

[The Notes of the case are abridged from the record of Mr. WILliaM HILL, M. B. Lond., Registrar and Pathologist to the Hospital.] G. W., aged 61 , occupied in a timber yard, applied at the hospital as an out-patient, on November 1st, 1886.

History. - He had first noticed hoarseness of voice, and occasional tickling cough, about two years ago; he had never suffered pain, or anything approaching inconvenience in breathing, except when hurrying to catch a train or omnibus. Gargles, etc., failing to give relief, he was advised by his family attendant, Dr. Gordon, of New Cross, to apply at this hospital.

The patient was a hale looking man for his age, 5 feet 6 inches in height, and weighing 166 pounds. The cause of his hoarseness was at once revealed on examination with the laryngoscope, which showed that while both rocal cords were congested, the left cord was immo. bile and ulcerated at its posterior portion. There was at that time but little thickening of the left ventricular band, and of the tissues of the left laryngeal boundary of the pharynx, as is seen by reference to Fig 1 , which was drawn six weeks after his first applying at the hos-

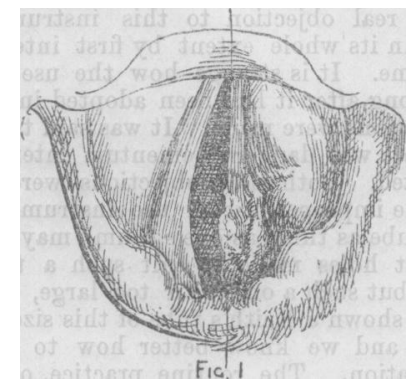

Laryngoscopic appearance prior to operation.

pital. There was neither then, nor indeed at any period, involvement of the cervical glands, nor was there any constitutional symptom point. ing to malignity. There did not appear any outgrowth projecting sufficiently to justify attempts at removal of a portion for the purpose of microscopic investigation. As the patient admitted hav. ing suffered from gonorrbœa some twenty-five years previously, it was decided to submit him to a course of biniodide of mercury, in view of the possibility of a venereal cause for his trouble. This treatment was pursued for six weeks, applications of a solution of sulphate of copper being also made to the larynx twice a week. Under these measures the patient expressed himself much relieved, but there could be no doubt that the ulceration was extending, and there was decided diminution in weight; for on December 13th he weighed only 160 pounds, a loss of 6 pounds in six weeks. It was therefore decided by Mr. Lennox Browne, after consultation with his colleagues, to attempt removal of the diseased half of the larynx, and the patient was admitted into the "Adelina Patti" iWard on December 13th. The operation was performed on the morning of the 15th, Mr. Carmalt Jones administering chloroform, Dr. Dundas Grant, Messrs. Percy Jakins and Hill assisting. Dr. Orwin (prevented from rendering active aid through temporary disablement of the hand) and Dr. Gordon were also present.

The operation, which lasted an hour and a half in all, may be conveniently divided into four stages.

1. A high tracheotomy between the second and third rings, and the introduction of Hahn's tampon-cannula, consisting of a tube surrounded by compressed sponge. This was first dipped in a solution of corrosive sublimate $(1$ in 5,000$)$.

2. An interval of twenty minutes for expansion of the tampon; anæsthesia being maintained by the administration of chloroform through the tracheal tube.

3. Thyrotomy - The median incision was extended from just above the tracheal opening to the lower margin of the hyoid bone, and all the tissues were carefully divided on a director until the thyroid cartilage was reached. The soft parts over the thyroid and cricoid cartilages were rasped sub-perichondrially, the raspatory being kept so close that the perichondrium was literally peeled away from he cartilage, whilst its relation to the superficial soft parts remained undisturbed. The separation was carried back by this means as far as the median line of the boundary between the larynx and pharynx. no scissors, knife, or other instrument than the raspatory was used. A horizontal incision over the hyoid bone, as recommended by Hahn, was not necessary, the vertical one proving amply sufficient, but part of the hyoid attachment of the thyro-hyoid muscle was severed; the much ossified thyroid cartilage was then divided by cutting forceps along its centre; the wings were separated by retractors, and the growth was seen to be confined entirely to the left half of the larynx, which portion it was decided to remove.

4. Laryngectomy was effected by $(a)$ further careful and thorough separation of the attachments to the pharynx by raspatory, knifehandle, and finger-nail; $(b)$ division of the thyro-hyoid membrane, as close as possible to its thyroid attachment ; $(c)$ division of the left superior horn of the thyroid cartilage at its root by cutting pliers ; (d) division in the median line of the cricoid cartilage, before and behind, with pliers; $(e)$ the divided half of the larynx was then separated from the first ring of the trachea, and a few nicks only were necessary to remove it entire. 